\title{
Successful reversal of chronic incapacitating post-TIPS encephalopathy by balloon occlusion of the stent
}

\author{
Daphna Fenyves mD, Michel P Dufresne MD, Jean Raymond mD, Michel Lafortune mD, \\ BERNARD WILLEMS MD, GILLES POMIER-LAYRARGUES MD
}

D Fenyves, MP DuFresne, J RAYMOND, M LAFORTune, B WILlems, G POMIER-LAYRARGUES. Successful reversal of chronic incapacitating postTIPS encephalopathy by balloon occlusion of the stent. Can J Gastroenterol 1994;8(2):75-80. Transjugular intrahepatic portosystemic shunt (TIPS) placement is a new technique allowing decompression of the portal system without the need for abdominal surgery or general anesthetic. This promising procedure appears safe, and is being evaluated in the context of life threatening uncontrollable variceal hemorrhage as well as ascites refractory to medical treatment. Following TIPS, portal flow diversion is associated with hepatic encephalopathy in up to $25 \%$ of patients. This is most often mild and treatable but may become uncontrollable, incapacitating and even life threatening in up to 3 to $5 \%$ of cases. The authors present two patients in whom such life threatening encephalopathy and stupor was reversed by transjugular balloon occlusion of the TIPS.

Key Words: Ascites, Encephalopathy, Portal hypertension, Transjugular intrahepatic shunt (TIPS)

\section{Traitement d'une encéphalopathie chronique invalidante après} shunt intrahépatique transjugulaire par occlusion de la prothèse à l'aide d'un ballonnet

RÉSUMÉ : Le shunt intrahépatique transjugulaire (SIT]) est une technique nouvelle qui permet de décomprimer le système porte sans qu'il soit nécessaire d'avoir recours à la chirurgie et à une anesthésie générale. Cette technique prometteuse apparaît sécuritaire et est actuellement évaluée dans le traitement des hémorragies par varices oesophagiennes incontrôlables, ainsi que de l'ascite réfractaire au traitement médical. Le shunt intrahépatique entraîne une diminu-

\section{continued on next page}

Liver Unit and Department of Radiology, Hôpital Saint-Luc and Université de Montréal, Montreal, Quebec

Correspondence: Dr Daphna Fenyves, Hôpital Saint-Luc, 264, René-Lévesque east,

Montreal, Québec H2X 1P1

Received for publication September 3, 1993. Accepted December 15, 1993
HEMAJOR COMPLICATION OFPOR-
tal hypertension and primary cause of death in cirrhotics remains variceal rupture. It carries a high morbidity and mortality (1), is often associated with deteriorating liver function, and may thus make the need for eventual organ replacement even more imminent in patients with chronic liver disease.

Despite available hemostatic procedures, including balloon tamponade and endoscopic sclerotherapy, the hemorrhage may be uncontrollable. A more definitive intervention is then required. Unfortunately in cirrhotics with more advanced underlying liver disease, the morbidity and mortality rates associated with shunt surgery remain prohibitive. These potential candidates need another option to prevent them from succumbing to hemorrhage and to provide a 'bridge' until organ replacement (2).

Such a life-saving procedure is the transjugular intrahepatic portosystemic shunt (TIPS). The technique consists of transjugular placement of an intravascular stent into the liver parenchyma to connect the portal and hepatic veins $(3,4)$. This creates a shunt, thus decompressing the portal system without the 
tion importante du débit portal qui peut être compliquée d'une encéphalopathie hépatique chez plus de $25 \%$ des patients. Celle-ci est la plupart du temps modérée et facilement traitable, mais peut devenir incontrôlable, incapacitante, et même mettre la vie du patient en danger dans 3 à $5 \%$ des cas. Les auteurs présentent deux cas chez qui une telle encéphalopathie gravissime a pu être traitée de façon efficace par l'occlusion du shunt au moyen d'un ballonnet mis en place par voie transjugulaire.

\section{TABLE}

Hepatic manometry pre- and post-transjugular intrahepatic shunt (TIPS)

\begin{tabular}{lcccc}
\hline & \multicolumn{2}{c}{ Case 1 } & \multicolumn{2}{c}{ Case 2 } \\
& Pre-TIPS & Post-TIPS & Pre-TIPS & Post-TIPS \\
\hline Inferior vena cava pressure $(\mathrm{mmHg})$ & 2 & 10 & 14 & 11 \\
Portal venous pressure $(\mathrm{mmHg})$ & 27 & 18 & 37 & 20 \\
Portohepatic gradient $(\mathrm{mmHg})$ & 25 & 8 & 23 & 9 \\
\hline
\end{tabular}

need for a general anesthetic or intraabdominal surgery. The procedure, being evaluated in several centres, shows promise. It seems effective in arresting hemorrhage from variceal rupture and, in experienced hands, appears relatively safe (5-10). In light of good initial results, TIPS is also being evaluated for use in intractable ascites (11-14).

Successful portal decompression by the creation of a portosystemic shunt is accompanied, as is its surgical counterpart, by the development of chronic encephalopathy in up to a quarter of patients (15-17). This can often be controlled with medications; however, severe intractable hepatic encephalopathy and/or progressive liver failure occur and present a serious problem.

We describe two patients in whom placement of TIPS for intractable ascites resulted in the development of severe, intractable hepatic encephalopathy and coma, and in whom complete reversal was achieved by permanently occluding the intrahepatic stent shunt.

\section{CASE 1 PRESENTATION}

The patient was an 80 -year-old male suffering from myeloid metaplasia, which has slowly evolved over the past 15 years. The disease was accompanied by portal hypertension and increasing ascites, with an associated umbilical hernia and important peripheral edema (treated with diuretics since December 1991).

From March 1992, following variceal rupture, the patient underwent re- peated monthly ethanolamine oleate injections and achieved complete variceal eradication by October 1992. The patient was then left with massive ascites resistant to diuretic therapy and associated with chronic renal insufficiency (creatinine approximately 185 to $190 \mu \mathrm{mol} / \mathrm{L})$, necessitating paracentesis of 6 to $8 \mathrm{~L}$ every two to three weeks (as of March 1992).

On October 21, 1992, the patient was readmitted with massive ascites accompanied by a tense protuberant, excoriated umbilical hernia and massive leg edema. He was on a 'no added salt' diet, and his medication included aldactone $150 \mathrm{mg}$ and furosemide 60 mg daily.

The patient was alert and oriented, pale, cachectic, with absence of icterus or stigmata of chronic liver disease and, in particular, no encephalopathy. He was perfectly lucid with no flapping. Initial laboratory investigations revealed: hemoglobin $90 \mathrm{~g} / \mathrm{L}$; white blood cell count 12,100 cells $/ \mathrm{mm}^{3}$; platelet count 238,000 cells $/ \mathrm{mm}^{3}$; prothrombin time/partial thromboplastin time normal; bilirubin $24 \mu \mathrm{mol} / \mathrm{L}$; aspartate aminotransferase $22 \mathrm{IU} / \mathrm{L}$; alanine aminotransferase $11 \mathrm{IU} / \mathrm{L}$; alkaline phosphatase $546 \mathrm{IU} / \mathrm{L}$; albumin $34 \mathrm{~g} / \mathrm{L}$; urea $25.8 \mathrm{mmol} / \mathrm{L}$; creatinine $254 \mu \mathrm{mol} / \mathrm{L}$; sodium 134; potassium 5.3; chloride $105 ; 24 \mathrm{~h}$ urinary sodium excretion $6 \mathrm{mmol}$; and creatinine clearance 0.17 $\mathrm{mL} / \mathrm{s}$ (normal 1.2 to 2.4 ). After initial stabilization including further paracentesis, it was decided to provide more definitive treatment due to fear of potential umbilical hernia rupture.

On October 29, under antibiotic coverage and after informed consent was obtained, an intrahepatic portosystemic stent shunt was placed via the transjugular approach as previously described and without complications (6). Prior abdominal Doppler examination had shown a patent porto-spleno-mesenteric axis with hepatopedal flow in all except the inferior mesenteric vein (where flow was reversed). There was a small patent para-umbilical vein with hepatofugal flow. The coronary vein was not visualized.

The baseline and post-TIPS hepatic manometric values are summarized in Table 1. Liver biopsy done during the procedure revealed a large number of megakaryocytes within the sinusoids as well as discrete sinusoidal fibrosis, all compatible with the underlying diagnosis of myeloid metaplasia.

Abdominal Doppler examination one week following TIPS placement confirmed a patent shunt between the right portal and hepatic veins. The para-umbilical vein was no longer patent and the inferior mesenteric vein had a reversed but slower flow. Bloodflow in the right portal radicals was hepatofugal, and that in the left intrahepatic portal radicals was back and forth. Ascites were still present.

The patient was well for the first week post-TIPS but then developed encephalopathy. It was initially mild and treatable (grade I to II) but became progressively more severe and more difficult to control (grade III) despite persistent absence of any precipitating factors. The patient kept fluctuating between a grade II and III encephalopathy over a period of two weeks despite progressive and additive use of lactulose up to $15 \mathrm{~mL}$ qid, metronidazole $250 \mathrm{mg}$ bid and finally sodium benzoate $3 \mathrm{~g}$ tid. On November 25, the patient's level of consciousness deteriorated further and he became comatose within the ensuing three days. It was decided to see if occlusion of the intrahepatic shunt was feasible and could achieve restoration of portal perfusion and reversal of the hepatic coma.

On November 28, the prostheses 
and portal vein were cannulated via the transjugular approach, demonstrating all portal venous flow to be diverted through the shunt. The inferior vena cava pressure was $11 \mathrm{mmHg}$ and the portal venous pressure was $20 \mathrm{mmHg}$, resulting in a portohepatic gradient of $9 \mathrm{mmHg}$. The stent was blocked with an angioplasty balloon $(10 \mathrm{~mm} \times 4 \mathrm{~cm}$, Cook Canada) dilated to its maximum diameter using weak pressure; this resulted in an increase in portal venous pressure to $40 \mathrm{mmHg}$. Injection of contrast material into the portal vein after shunt occlusion revealed the immediate re-opacification of the right and left intrahepatic vein branches. The balloon catheter was secured at the neck for evaluation of the effect of this temporary manoeuvre on the patient's level of consciousness before proceeding to a more permanent solution.

Within $24 \mathrm{~h}$ the patient was fully awake. The TIPS was then occluded in a definitive fashion under antibiotic cover on November 30 . Using a standard neuroangiographic technique routinely used for carotid occlusion (25), a latex balloon (Debrun \#9, Nycomed Ingenor, Paris, France), hand-tied with an elastic ligature to a microcatheter (Tracker 10, Target Therapeutic, California), was placed within the shunt just above the portal segment of the prosthesis. It was inflated with contrast material until it was secured against the wall of the stent $(10 \mathrm{~mm})$, then released in that position by traction on the microcatheter. It was shown to occlude the shunt completely on angiographic control. The procedure was well tolerated. The patient remained completely alert and lucid despite cessation of metronidazole, sodium benzoate and lactulose.

The ascites re-accumulated rapidly, necessitating paracentesis one week following complete blockage of the shunt. An abdominal Doppler examination 10 days after the intervention showed the presence of a patent paraumbilical vein and hepatopedal flow in the intrahepatic portal veins. Two and a half months later, the patient was well but required paracentesis ( $8 \mathrm{~L}$ ) every two weeks. He had no encephalopathy and was not on any medication.

\section{CASE 2 PRESENTATION}

A 65-year-old male with alcoholic cirrhosis who had been abstinent since March 1991 presented with cachexia, spider angioma, increased abdominal girth and bilateral leg edema. Investigations ruled out other etiologies for the underlying liver disease. A transjugular manometry and biopsy at that time confirmed the cirrhosis with associated portal hypertension. Endoscopy showed the presence of esophageal varices grade III/IV.

Over the ensuing seven months, the patient received successively triamterene, furosemide, metolazone and amiloride for massive ascites. He required constant adjustments in diuretic therapy due to insufficient effect and increasing creatinine levels. From October 1991, the patient required paracentesis ( 8 to $10 \mathrm{~L}$ at a time) every two weeks; the diuretics were discontinued due to development of the hepatorenal syndrome.

The patient was admitted in April 1992 for consideration of intrahepatic shunt placement. He had a moderately advanced hepatic insufficiency (Pugh score 9). Baseline values were: $24 \mathrm{~h}$ urinary sodium excretion $15 \mathrm{mEq}$; urea $14.2 \mathrm{mmol} / \mathrm{L}$; creatinine $186 \mu \mathrm{mol} / \mathrm{L}$; and creatinine clearance $0.44 \mathrm{~mL} / \mathrm{s}$ (normal 1.2 to 2.4). An abdominal ultrasound and Doppler examination revealed the presence of a patent porto-spleno-mesenteric axis; portal flow was hepatopedal.

On April 22, a TIPS was performed. Baseline and post-TIPS manometry are shown in Table 1 . The procedure was well tolerated with no immediate complications. A control abdominal Doppler examination one week following the procedure confirmed a patent stent shunt between the right portal and hepatic veins. The left intrahepatic portal bloodflow was still hepatopedal whereas in the right lobe, bloodflow exhibited back and forth motion.

The patient required two subsequent shunt revisions in July and $\mathrm{Oc}_{\mathrm{c}}$ tober 1992, the last one 5.5 months following the original procedure, for partial obstruction at the portal and hepatic vein extremities, respectively. These revisions resulted in a porto- hepatic gradient reduction from 25 to 17 and finally $9 \mathrm{mmHg}$.

Three weeks after the second shunt revision, the patient was admitted with an episode of confusion thought to have been precipitated by dehydration. He was rehydrated, but also required treatment with lactulose $30 \mathrm{~mL}$ qid and metronidazole $250 \mathrm{mg}$ bid. After three weeks he was discharged, alert and oriented on these medications as well as on triamterene $50 \mathrm{mg}$ and furosemide $40 \mathrm{mg}$ daily for a moderate residual ascites.

On November 29, seven weeks after the last shunt revision, the patient was admitted with increasing encephalopathy (grade III), again with no obvious precipitating cause. His level of consciousness progressively declined and he became comatose within the ensuing $72 \mathrm{~h}$. Because of the catastrophic deterioration, on December 3, two months after the last shunt revision, the patient underwent catheterization of the intrahepatic shunt with a view to evaluate the effect of temporary stent occlusion on his level of consciousness. Baseline manometry revealed: inferior vena cava pressure $8 \mathrm{mmHg}$; portal venous pressure $18 \mathrm{mmHg}$; and portohepatic gradient $10 \mathrm{mmHg}$. Portography showed passage of the dye via a patent portohepatic shunt, with absence of opacification of the intrahepatic portal vein branches (Figure 1). An angioplastic balloon $(10 \mathrm{~mm} \times 4 \mathrm{~cm}$, Cook Canada) was dilated and left in place within the stent shunt, resulting in an immediate increase of the portal venous pressure to $39 \mathrm{mmHg}$ and opacification of the previously absent intrahepatic portal veins (Figure 2). The balloon catheter was secured at the neck for evaluation of this temporary manoeuvre on the patient's level of consciousness.

Within 24 h of shunt blockage, the patient was awake, although still slow and not fully oriented. Because of this dramatic though partial recovery, the TIPS was occluded permanently on December 4 using a detachable latex balloon (Debrun \#9) inflated to $10 \mathrm{~mm}$ as described in the previous case. Angiographic control confirmed complete occlusion of the shunt with asso- 


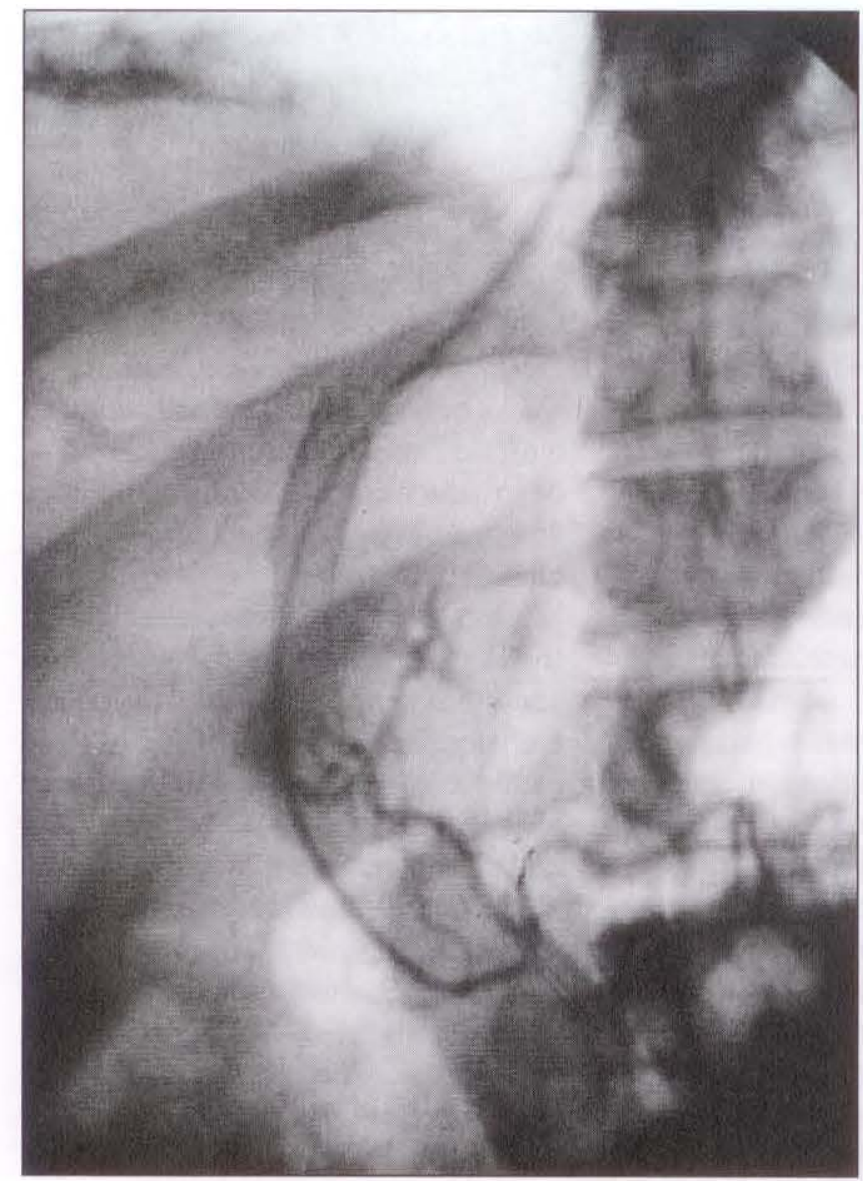

Figure 1) Intrahepatic stent shunt in position between the right portal and hepatic veins. Injection of contrast material in the main portal vein trunk is followed by immediate wash-out of the dye via the shunt, with total absence of opacification of any intrahepatic portal vein branches

Figure 2) Upper right Intrahepatic shunt is occluded using a balloon with immediate re-opacification of intrahepatic portal vein branches

Figure 3) Lower right Permanent occlusion of the intrahepatic shunt with a dilated balloon left in place within the stent
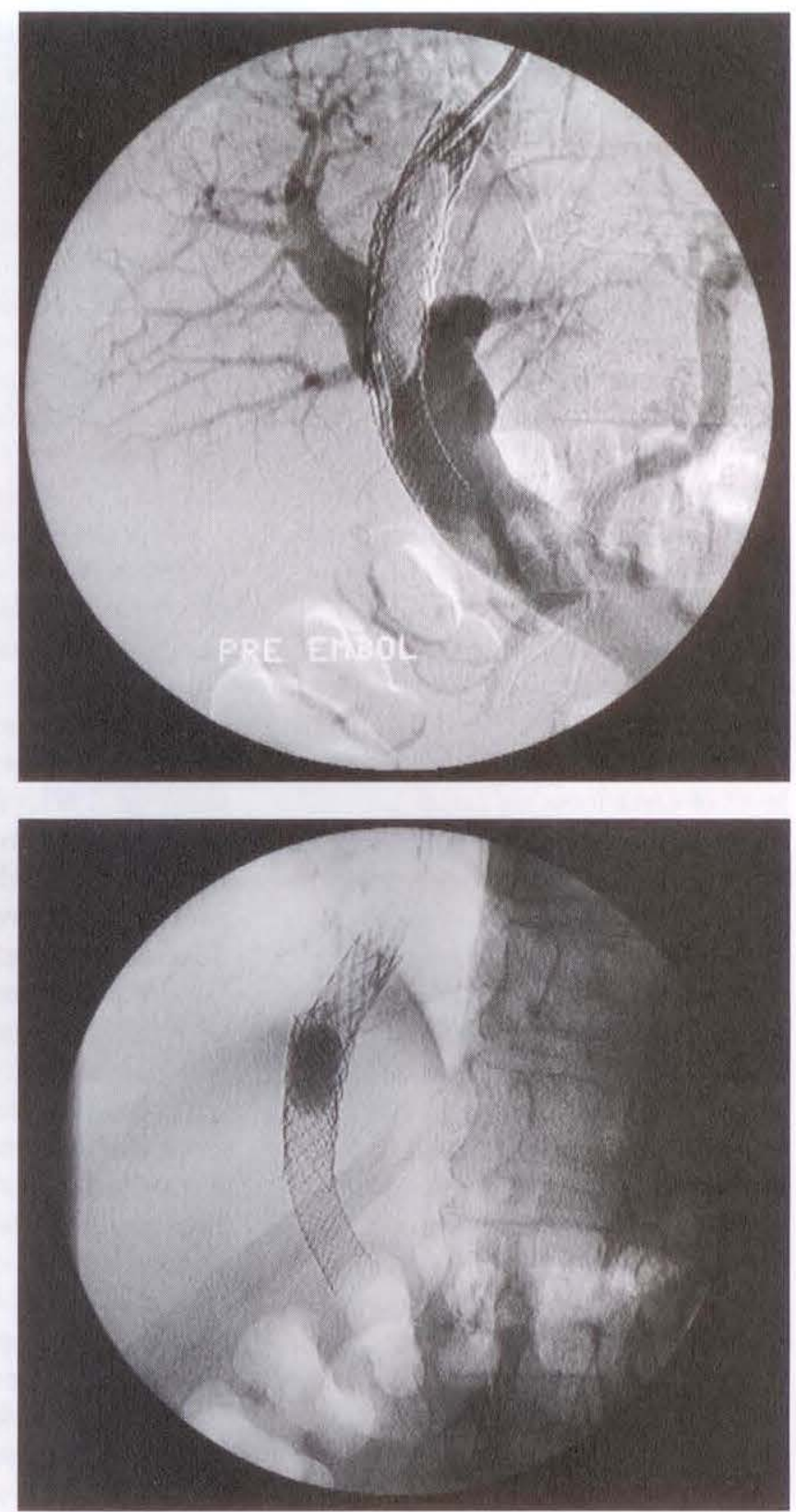

ciated refilling of the intrahepatic portal branches (Figure 3). The procedure was well tolerated. Follow-up Doppler examination revealed a return of hepatopedal flow in both right and left intrahepatic portal branches. In addition, there was re-accumulation of ascites and a left pleural effusion.

The patient's level of consciousness continued to improve; he was fully oriented and lucid five days later. He was discharged on December 12 (nine days after permanent shunt occlusion) without any specific treatment for encephalopathy.

The ascites is being treated on an out-patient basis, with repeated paracentesis every two weeks. On March 10, 1993, three months after shunt occlusion, the patient presented with an esophageal variceal rupture. He was successfully treated with sclerotherapy and has embarked on monthly injections for full eradication of the varices. Encephalopathy never recurred despite cessation of all specific treatment.

\section{DISCUSSION}

We presented two patients in whom severe disabling chronic recurrent encephalopathy, occurring following creation of an intrahepatic shunt, was reversed by transjugular balloon occlusion of the stent.

TIPS placement is a promising new technique that allows portosystemic decompression by creating an intrahepatic shunt without the need for a general anesthetic or laparotomy. It can be a life-saving procedure in the face of otherwise uncontrollable variceal hemorrhage, and may become a useful tool in the management of intractable ascites. Surgical portal decompression with shunting of portal blood away from the liver and directly into the systemic circulation may result 
in chronic hepatic encephalopathy in approximately $25 \%$ of cirrhotics. This usually responds to medical therapy, but may become uncontrollable. Selective decompression with a distal splenorenal shunt does not appear to lessen the incidence of hepatic encephalopathy due to reversal of portal bloodflow (18). In addition, we are unable to predict who will develop encephalopathy following portal flow diversion (19).

As with its surgical counterpart, published reports on TIPS placement describe an incidence of hepatic encephalopathy ranging from 10 to $24 \%(15-17,20)$, with symptoms being uncontrollable, incapacitating and even potentially life threatening in 3 to $5 \%$ of cases. This is of particular concern as we gain confidence with the technique and expand its indications, offering TIPS to patients with a relatively well-preserved liver function or as an elective therapeutic alternative to those with intractable ascites who require repeated paracentesis, some before eventual liver transplantation but others mostly for a better quality of life.

Our first presented patient did not have any underlying chronic liver disease. His portal hypertension was related to a long-standing myeloproliferative disorder (21). Significant portal flow diversion, even in the absence of underlying liver dysfunction, can lead to severe hepatic encephalopathy as our patient clearly demonstrated.

For patients with chronic liver disease, it has been suggested that pre-TIPS Pugh score is not predictive of postprocedure encephalopathy, and that advanced age, larger shunt diameter and greater shunt flow may all contribute

\section{REFERENCES}

1. Smith JL, Graham DY. Variceal hemorrhage. A critical evaluation of survival analysis. Gastroenterology 1982;82:968-73.

2. Fenyves D, Huet PM, PomierLayrargues G, Villeneuve JP, Willems B. Management of portal hypertension. Contemp Gastroenterol 1993;1:12-20.

3. Gordon JD, Colapinto RF, Abecassis M. Transjugular intrahepatic portosystemic shunt: a non-operative approach to life-threatening towards a higher risk $(16,17)$. Predicting the onset of this complication following diversion of portal flow will likely remain a difficult task since the trigger is probably multifactorial.

It is possible to reverse encephalopathy following surgical portal flow diversion by operative ligation of the shunt (except end-to-side portacaval anastomosis) and restoration of portal perfusion $(22,23)$. Unfortunately, this is accompanied by a high operative mortality, especially in those with associated marked liver dysfunction. Recently, Potts et al (24) demonstrated the restoration of hepatorenal flow with reversal of disabling encephalopathy and improved liver function by balloon occlusion of a portorenal graft shunt without need for a laparotomy.

Faced with a life threatening situation, we attempted transjugular occlusion of the intrahepatic shunts. The balloon occlusion method used in these two patients is a well-recognized technique for permanent occlusion of carotid arteries and carotid cavernous fistulae $(25,26)$. When latex balloons are filled with contrast material, they slowly deflate over several months, by which time the formation of an organized thrombus has already long ensured permanent obliteration (27). Inadvertent detachment of a latex balloon used for occlusion of intracranial aneurysms has been described (28). The risk of such an event occurring in the present context, however, is minimal since the latex balloon, hand-tied with elastic ligatures, is difficult to detach, and must be adequately secured against a rigid tubular structure to allow it to be pulled away and released from its microcatheter. We prefer this to the com-

variceal bleeding. Can J Surg 1987:30:45-50.

4. Richter GM, Noelge G, Palmaz JC. The transjugular intrahepatic porto-systemic stent-shunt (TIPS): results of a pilot study. Cardiovasc Intervent Radiol 1990;13:200-7.

5. Zemel G, Katzen BT, Becker GJ, Benenati JF, Sallei S. Percutaneous transjugular porto-systemic shunt. JAMA 1991;266:390-3.

6. Bilodeau M, Rioux L, Willems B, Pomier-Layrargues G. Transjugular intrahepatic portacaval stent mercially available balloon systems that are equipped with a self-sealing valve and deliberately easier to detach (ITC, California). In addition, should such a contrast-filled balloon migrate and cause occlusion of an important vessel, it can be perforated under fluoroscopic guidance using a 22 gauge needle.

Onset of chronic disabling encephalopathy after TIPS is a serious problem. Unfortunately, once in place and dilated, the stent cannot be reduced in size in an attempt to decrease the amount of portal flow diversion while preserving some advantage of the shunting procedure with respect to management of intractable ascites or variceal rupture. Furthermore, in our experience, initial 'down' calibration of the shunt diameter results in insufficient flow diversion and necessity of further dilation and shunt revisions to decompress the portal system adequately and to render the shunt efficacious.

\section{CONCLUSIONS}

The authors demonstrated the feasibility, safety and ease of shunt obliteration using transjugular balloon occlusion of the stents, with consequent reversal of the hepatic coma. In addition, such shunt occlusion did not induce portal vein thrombosis and thus did not endanger any eventual liver transplantation. It is paramount, however, as these cases clearly demonstrate, that very strict criteria be used to select patients for TIPS.

ACKNOWLEDGEMENTS: The authors thank D Guérette for technical assistance and $\mathrm{M}$ Bourcier for manuscript preparation.

shunt as a rescue treatment for life threatening variceal bleeding in a cirrhotic patient with severe liver failure. Am J Gastroenterol 1992;87:369-71.

7. Fenyves D, Willems B, Lafortune M, Dauzat M, Pomier-Layrargues G. Hemodynamic effects of transjugular intrahepatic porto-systemic stent shunt (TIPS) in cirrhotic patients. J Hepatol 1992;16(Suppl 1):S36.

8. Ring EJ, Lake JR, Roberts JP. Using transjugular intrahepatic portosystemic shunts to control variceal bleeding 
before liver transplantation. Ann Intern Med 1992;116:304-9.

9. Vinel JH, Rousseau H, Bilbao JL, et al. Transjugular intrahepatic portocaval shunts (TIPS) using the Wallstent endoprosthesis: prospective study in 66 patients. Hepatology 1992;16:85A. (Abst)

10. Garcia-Villareal L, Zozaya JM, Quiroza J, et al. TIPS for portal hypertension and liver cirrhosis. J Hepatol 1992;16(Suppl):91A. (Abst)

11. Sanyal AJ, Freedman AM, Shifman ML. Transjugular intrahepatic portosystemic shunt for ascites: a preliminary report. Am J Gastroenterol 1992;87:1305. (Abst)

12. Ochs A, Sellinger M, Haag Kn. Transjugular intrahepatic portosystemic stent shunt (TIPS) for the treatment of refractory ascites and hepatorenal syndrome: results of a pilot study. Gastroenterology 1992;102:A862. (Abst)

13. Pomier-Layrargues $G$, Legault L, Roy L, Dufresne MP, Lafortune M, Fenyves D. TIPS for treatment of refractory ascites: a pilot study. Hepatology 1993; 18:103A.

14. Garcia-Villareal L, Zozaya JM, Quiroga J, et al. Transjugular intrahepatic portosystemic shunt (TIPS) for intractable ascites (IA): Preliminary results. J Hepatol 1992:16(Suppl):S36. (Abst)

15. Sanyal AJ, Freedman AM, Shiffman ML. Portosystemic encephalopathy (PSE) following transjugular intrahepatic portosystemic shunt
(TIPS): a controlled study. Hepatology 1992;16(Suppl):85A. (Abst)

16. Sellinger $M$, Ochs $A$, Haag K. Incidence of hepatic encephalopathy and follow-up of liver function in patients with transjugular intrahepatic portosystemic stent-shunt (TIPS). Gastroenterology 1992;102:A883. (Abst)

17. Somberg KA, Riegler JL, Doherty M, et al. Hepatic encephalopathy following transjugular intrahepatic portosystemic shunts (TIPS): incidence and risk factors Hepatology 1992:16(Suppl):122A. (Abst)

18. Lacy AM, Navasa M, Gilabert R, et al. Long-term effects of distal splenorenal shunt on hepatic hemodynamics in liver function in patients with cirrhosis: importance of reversal of portal blood flow. Hepatology 1992;15:616-22.

19. Pomier-Layrargues G, Huet PM, Infante-Rivard C, et al. Prognostic value of indocyanine green and lidocaine kinetics for survival and chronic hepatic encephalopathy in cirrhotic patients following elective end-to-side portacaval shunt. Hepatology 1988;8:1506-10.

20. Laberge JM, Ring EJ, Gordon RL, et al. Creation of a transjugular intrahepatic portosystemic shunts with the Wallstent endoprosthesis: results in 100 patients. Radiology 1993; 187:413-20.

21. Dubois A, Dauzat M, Pignodel C, et al. Portal hypertension in lymphoproliferative and myeloproliferative disorders: hemodynamic and histologic correlations. Hepatology 1993; 17:246-50.

22. Chandler RJG, Fechner RE. Hepatopedal flow restoration in patients intolerant of total portal diversion. Ann Surg 1983;197:574-81.

23. Hanna SS, Smith RS, Henderson JM, Millikan WJ, Warren WD. Reversal of hepatic encephalopathy after occlusion of total portasystemic shunts. Am J Surg 1981;142:285-9.

24. Potts JR, Henderson JM, Millikan WJ, Jones P, Warren WD. Restoration of portal venous perfusion and reversal of encephalopathy by balloon occlusion of portal systemic shunt. Gastroenterology 1984;87:208-12.

25. Raymond J, Fontaine S, Dufresne MP, et al. L'occlusion de la carotide par ballonnet détachable - Indications, résultats, et complications. Radiology 1990;10:299-303.

26. Debrun G, Lacour P, Caron JP, Hurth M, Comoy J, Keravel Y. Detachable balloon and calibrated-leak balloon techniques in the treatment of cerebral vascular lesions. J Neurosurg 1978;49:635-49.

27. Debrun G, Lacour P, Caron JP, et al. Inflatable and released balloon technique. Experimentation in dogapplication in man. Neuroradiology 1975;9:267-71.

28. Lasjaunias P, Berenstein A. Surgical Neuroangiography, vol II.

Endovascular Treatment of Craniofacial Lesions. New York: Springer Verlag, 1987:175-233. 


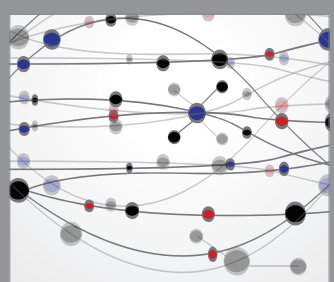

The Scientific World Journal
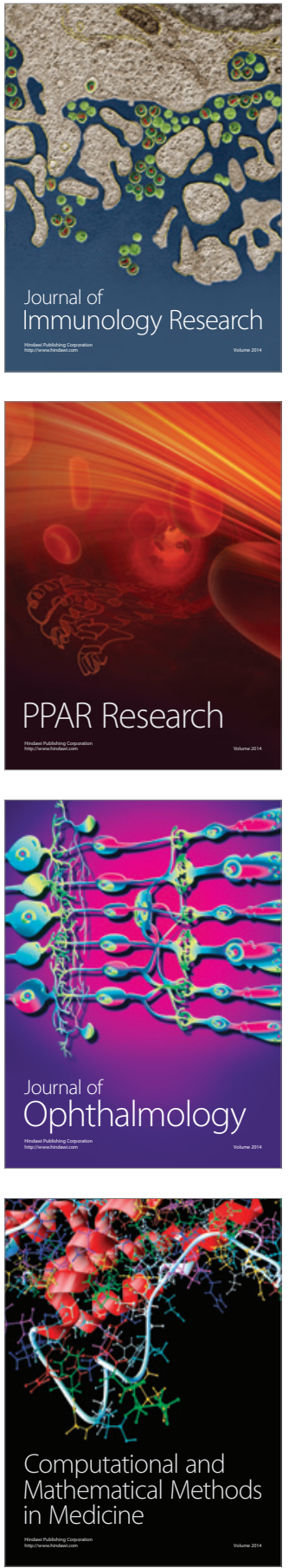

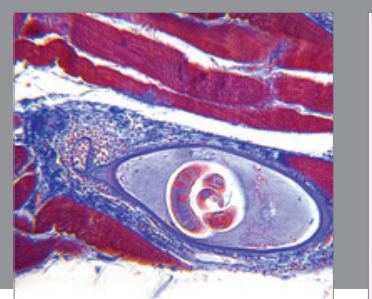

Gastroenterology Research and Practice

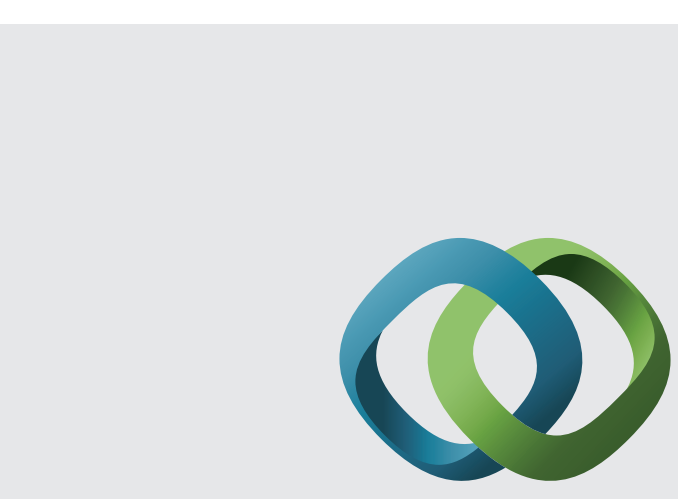

\section{Hindawi}

Submit your manuscripts at

http://www.hindawi.com
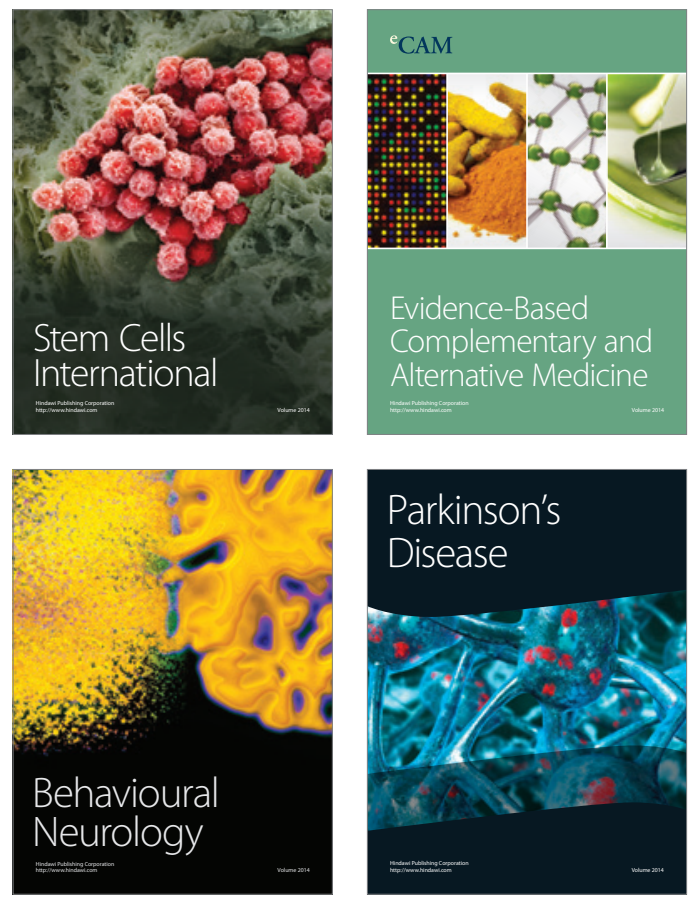


Disease Markers
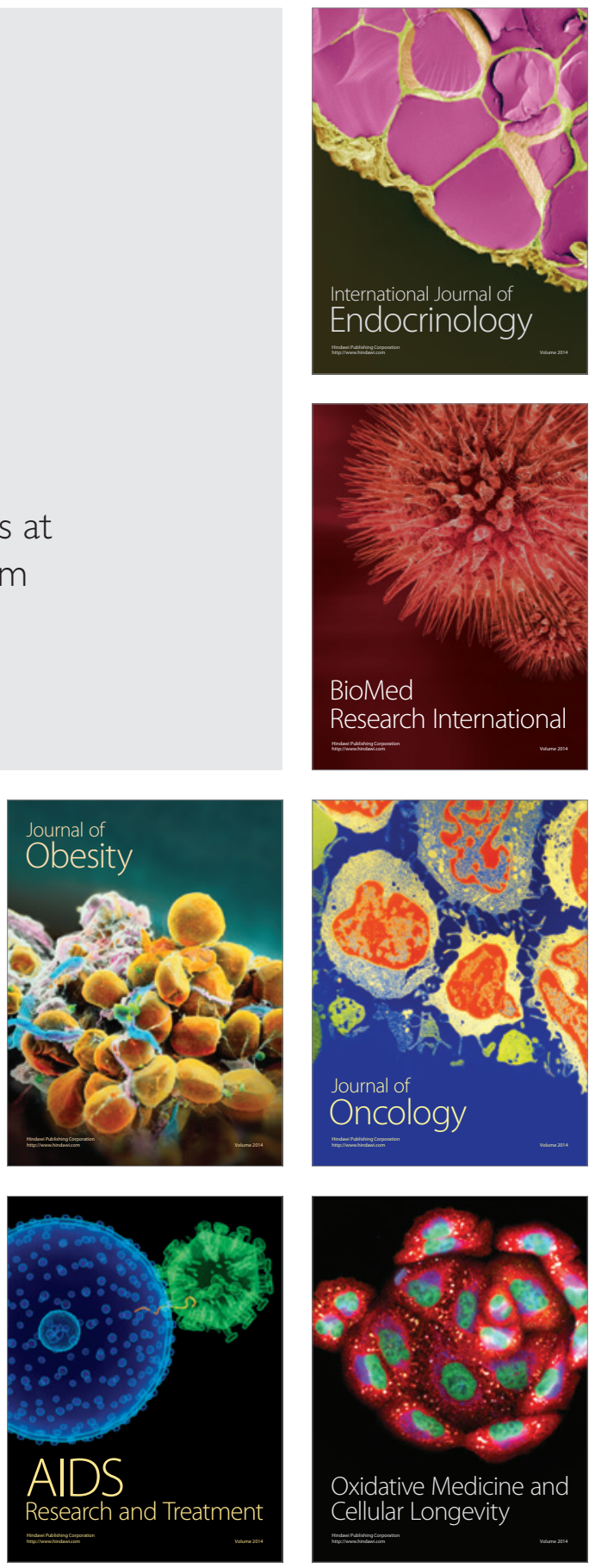